\title{
Editorial Introduction: Re-envisioning Education in a Globalizing World
}

\author{
Hiro Saito \\ Singapore Management University \\ hirosaito@smu.edu.sg
}

\begin{abstract}
This special issue focuses on education as a crucial factor mediating the relationship between youth and globalization. Specifically, four papers collectively explore how education can be re-envisioned from the following vantage point: the use of technology to foreground the fundamentally interconnected nature of today's world; the help of mindfulness to deepen the awareness of such interconnectedness and cultivate a commitment to collective well-being; the role of activism to produce more critical knowledge and transformational solidarity for social justice on a global scale; at the same time, the necessity of reflexivity to examine one's own ontological and epistemological assumptions before attempting any educational intervention. I argue that this vantage point helps re-envision the existing institutions and practices of education to encourage young people in a globalizing world to learn to live a happy life together by embracing their pluriversal coexistence.
\end{abstract}

\section{Keywords}

cosmopolitics - global citizenship - happiness - interbeing - social justice - university

This special issue Re-envisioning Education in a Globalizing World focuses on education as a crucial factor mediating the relationship between youth and globalization. To begin with, educational institutions and practices powerfully shape young people's lives - their aspirations, beliefs, identities, skills, future livelihoods, and so on. Of course, young people are not passive receivers of education, as they constantly exercise their own agency in critically and creatively appropriating what their teachers, parents, and other older people in society try to pass down (Corsaro, 2018); globalization also directly impacts young 
people's lives, enabling the emergence of global youth culture and identity outside of educational institutions and practices (Cicchelli and Octobre, 2019; Nilan and Feixa, 2006). Nevertheless, young people's agency presupposes the existence of institutions and practices to be appropriated in the first place and, in the contemporary world, education has remained a central node in the network of everyday activities in which new generations are born and brought up.

At the same time, educational institutions and practices have been undergoing significant changes because of globalization, i.e. the growing transnational flows, interactions, and connections of people, cultures, economies, and governments (Burbules and Torres, 2000; Suárez-Orozco and Qin-Hilliard, 2004). Examples of these changes include, just to name a few, increasing international student mobility in various forms, ranging from study abroad to migration; reform of curricula and pedagogies to prepare students for dealing with climate change, refugee crises, and other urgent global issues; and reorientation of teaching and research in the face of various isomorphic mechanisms, such as international student assessments and world university rankings. Globalization thus has been pushing educational institutions and practices to evolve beyond their modern origin as central vehicles for nation-building (Saito, 2011).

This ongoing evolution of education has enormous consequences for young people in the present and the future. For example, if international student mobility continues to grow, younger generations may experience greater polarization of the job market (Brown and Tannock, 2009), e.g. competition for dominant positions in the global market vis-à-vis resignation to dominated positions in the local market. If school curricula emphasize the education of "strategic cosmopolitans" (Mitchell, 2003), younger generations may not fully develop ethical dispositions toward foreign others. If more and more universities focus on global competition, they may fail to provide meaningful education for the majority of younger generations whose lives are still embedded in specific locales and nation-states (Saito, 2018). These are but a few examples of how educational institutions and practices in a globalizing world can decisively shape the parameters of young people's lives.

This is why the second issue of Youth and Globalization sets out to explore various educational challenges posed by globalization as well as their implications for youth. To be sure, given the magnitude of these challenges, a large number of studies have been already conducted to investigate the intersection of education and globalization both empirically and normatively (e.g. Noddings, 2005; Spring, 2014; Stromquist and Monkman, 2014). In this respect, many researchers and practitioners around the world have been "re-envisioning education in a globalizing world" for some time now. The aim of this special issue, then, is to contribute to the worldwide conversation with four original 
papers that illuminate important but hitherto understudied issues intersecting with education and globalization.

Specifically, the first paper by Ron Darvin probes the intersection of technology, education, and globalization because, although the advancement of information and communication technologies (ICTs) has been indispensable for globalization (Castells, 2010; Latham and Sassen, 2009), ICTs have not figured prominently in the ongoing debate on education and globalization that normally takes technology as a context, rather than an object, of study. After Davrin's piece foregrounds the ICT-enabled interconnectedness of young people's lives today, the second paper by Ram Mahalingam introduces mindfulness to explore its ethico-educational implications for living in a globally interconnected world, building on the growing research on applied mindfulness (Grossman et al., 2004; Kabat-Zinn, 2003). As Mahalingam's piece frames the ethico-educational implications of mindfulness in terms of collective well-being, the third paper by Michael Kennedy and Merone Tadesse examines instances of collective action or activism across universities that address the issues of social justice, such as racism and imperialism - often neglected in the debate on education and globalization that tends to focus on various trends in internationalization and student mobilities (Brooks and Waters, 2011; Deardorff, de Wit, Heyl, and Adams, 2012). The fourth and final paper by Riyad Shahjahan continues with the critical reflections in Kennedy and Tadesse's piece to invite greater reflexivity into the existing discourse on education and globalization, calling on researchers and practitioners to scrutinize their own ontological and epistemological assumptions.

Thus, these four papers in the special issue collectively expand the scope of the worldwide conversation on "re-envisioning education in a globalizing world" from the vantage point of technology, mindfulness, activism, and reflexivity. It is important to note, however, that the following is my own dialogue with, rather than summary of, the four papers; specifically, I search for unexpected but fruitful connections between the four papers as well as broaden the implications of their main arguments in light of various literatures they can potentially speak to. With this editorial introduction, I invite readers, too, to engage in their own dialogues with the four papers, which I believe will help advance the worldwide conversation.

\section{Beyond the Hidden Curriculum of ICTs}

Thanks to the so-called ICT revolution, young people today readily access the internet and social media through which they can bypass formal education 
by sharing knowledge about the world and the know-how of various skills. In this regard, the ICT revolution may appear to enable "deschooling society" (Illich, 1971), to liberate educational activities from schools cum bureaucratic organizations and instead facilitate self-directed and collaborative learning at the societal level. Nonetheless, the ICT revolution has not led to the deestablishment of formal education; in fact, formal educational institutions have expanded to offer courses and degree programs in the ICT fields (e.g. programming) while deploying ICTs to digitize existing programs and deliver contents through online platforms (e.g. blended learning).

Such resilience of formal education owes much to the nature of the education system as "the secular religion of a modern society", as John Meyer (2000a: 208) observed à la Émile Durkheim. At school, for example, students learn how the universe or the economy works, how to collect and analyze data through a laboratory experiment or a survey, and so on-namely, they are schooled in a certain ontology and epistemology legitimated by the education system. This does not mean, however, that all students master the legitimate ontology and epistemology to the same degree. Hence the education system functions as a locus of society-wide stratification, distributing credentials as proxies of competence and as prerequisites for attaining various positions in society (Bourdieu, 1983).

As Ron Darvin illustrates, education systems around the world have begun to legitimate digital literacy as a key competence to be acquired by today's youth. Digital literacy is now regarded as not only indispensable for surviving and thriving in the ІСт-driven knowledge society but also as desirable for making learning activities more student-centered and collaborative. As digital literacy becomes part of formal education, however, it can also reinforce the "hidden curriculum": certain class-based assumptions about digital literacy, built into pedagogies, lesson plans, and classroom settings, risk disadvantaging students from lower socioeconomic backgrounds. To combat against the hidden curriculum of digital literacy, Darvin offers several useful suggestions, e.g. how to reconceive digital literacy education in a broader socioeconomic context and redistribute digital literacy instruction across the entire school curriculum. Thus critically reconstructed, Darvin argues, digital literacy can help "youth construct their identities as global citizens and reimagine their lives and careers in ways that transform the world."

But exactly how can critical digital literacy facilitate the education of global citizens? An answer to this question is far from straightforward, as education researchers continue to debate what "global citizen" should look like and, if being a global citizen is desirable and possible at all, what kind of curriculum and pedagogy can best facilitate the education of such a citizen (e.g. de Oliveira Andreotti and de Souza, 2012; Goren and Yemini, 2017; Osler and Starkey, 2003)? 
Nevertheless, digital literacy education can at least help students learn what is happening in various parts of the world and communicate with people across national borders, which is indispensable for developing an awareness of the interconnected nature of today's world as a prerequisite of global citizenship.

\section{Dignity as a Focal Point of Critical and Holistic Mindfulness}

Still, how can students deepen this awareness of interconnectedness so as to actually take actions in response to the suffering and needs of foreign others as well as global problems (Saito, 2010)? Ram Mahalingam takes on this question by exploring the ethico-educational implications of mindfulness for living in a globally interconnected world. As research on mindfulness has exploded in psychology and other-related fields during the last two decades (Creswell, 2017), education researchers have also begun to study the benefits of mindfulness for students and teachers (Meiklejohn et al., 2012; Schonert-Reichl and Roeser, 2016). Since this growing research on applied mindfulness focuses on individual well-being, however, it often neglects larger socioeconomic structures that systematically cause stress in the first place, as pointed out by a small but growing number of critically minded researchers and practitioners (Purser, Forbes, and Burke, 2016). Mahalingam builds on this critical perspective to investigate how mindfulness can help young people cultivate their commitments to caring for others, whether near or far, whom they are interconnected with.

To be sure, such awareness of interconnectedness and commitments to collective well-being have been already emphasized in the Plum Village Tradition (Hanh, 1993) and other traditions of engaged Buddhism (Kotler, 1999). But Mahalingam rearticulates these Buddhist traditions in the secular language of critical social science: setting "dignity" in the workplace as a focal point of mindfulness practices, he effectively connects the psychological research on mindfulness and well-being at the individual level to larger social issues, such as inequality and precarity under capitalism. As a result, his proposed framework makes mindfulness practices more approachable for both Buddhists and non-Buddhists, most of whom have to work under capitalism to make a living - here, dignity in the workplace serves as a common ground between people who want to address and alleviate the suffering of colleagues, clients, and others with whom they interact on a regular basis.

Moreover, Mahalingam foregrounds how the problem of dignity in the workplace intersects with gender, race, ethnicity, and other axes of power asymmetry in society, expanding the horizon of dignity beyond the dimension of class. In fact, he suggests, this circle of interconnectedness should be expanded not only across economic, social, cultural, and political boundaries but also toward 
the entire ecology of life on Earth without which humans cannot exist, in parallel with the advocates of ecological self and citizenship (Bragg, 1996; Dobson, 2003). He thus advances a critical and holistic model of mindfulness centered on dignity as "an embodied praxis... engagement with our lives that improves the individual and collective well-being."

Put another way, by connecting the individual and collective levels of wellbeing, Mahalingam shows that mindfulness practices can lead to both inner healing and outer action. On the one hand, the awareness of interconnectedness can help young people overcome a sense of alienation they may feel despite, or rather because of, their ICT-enabled hyper-connectivity. On the other hand, it can motivate them to reach out to those who are suffering, for solidarity with the other as a part of one's life has the potential to facilitate active interventions in the world.

3 Globalizing Knowledge Activism for Social Justice

While Mahalingam shifts the focus of mindfulness practices from individual well-being to collective action for dignity, Michael Kennedy and Merone Tadesse squarely focus on collective action - what they call "knowledge activism" - aiming to transform universities to produce more critical knowledge for social justice on a global scale. Their focus on universities is important because, if the education system is indeed "the secular religion of a modern society," the university can be regarded as "the temple" of this religion because it "produces and certifies the best and brightest citizens and the most complex and rarefied knowledge" (Stevens, Armstrong, and Arum, 2008: 134), i.e. the university codifies a legitimate ontology and epistemology to be disseminated through mass operations of primary and secondary schools. Indeed, faculty members at universities often function as "others" (Meyer, 200ob) or "high priests" who produce theoretical knowledges for school administrators, teachers, and other practitioners to rationalize their policies, curricula, and pedagogies. What is researched and taught at universities, then, has indirect but enormous influence on the rest of the education system.

Furthermore, when exploring how universities can be transformed to facilitate more critical discussions of social justice, it is useful to turn attention to elite US universities, as Kennedy and Tadesse do, because these institutions arguably constitute the epistemic center of the world, setting global standards and benchmarks of excellence in the emerging global field of higher education driven by world university rankings and other isomorphic mechanisms 
(Hazelkorn, 2015; Pusser and Marginson, 2013). That is, given their centrality in the globalizing knowledge networks, elite US universities deserve critical scrutiny: how they approach social justice, as well as how their approaches can be transformed, has important implications for other higher education institutions around the world.

Specifically, Kennedy and Tadesse illustrate how elite US universities, including their own Brown, have been historically implicated in "colonial and imperial injustices... [and] those thefts of land, labor, and life itself" involving the dispossession of indigenous people, the slavery of blacks, and the military, economic, and political dominance of the USA over the rest of the world. Precisely because elite US universities have been part and parcel of these injustices traversing the USA, Kennedy and Tadesse suggest, they are pivotal sites for promoting knowledge activism, challenging the existing structures of knowledge production and their resultant contents to become more inclusive and critical, while extending solidarities to similar epistemic struggles in other parts of the world through action, not just speech. In this sense, elite US universities are "obligatory passage points" (Callon, 1984) for globalizing knowledge activism.

Thus, the mobilization of knowledge activism and transformational solidarity via elite US universities has the potential to link a multitude of epistemic struggles against extant injustices around the world including, but not limited to, racism, imperialism, and socioeconomic inequality, and develop them into a larger and more unified movement. In other words, for social justice to be effectively incorporated into the heart of universities today, internationalization efforts in higher education must be simultaneously accompanied by collective actions for the decolonization and deimperialization of knowledge production (Alvares and Faruqi, 2014; Bhambra, Nisancioglu, and Gebrial, 2018) both inside and outside of the USA.

To mobilize such a global network of knowledge activism and transformational solidarity for social justice across universities, what strategies and tactics are necessary? This is a crucial question because an inspiring vision can turn into reality only through the nitty-gritty of daily operations in higher education. Indeed, critically minded researchers and practitioners have already begun to explore the question, focusing on how to promote the publicness of universities as producers of knowledge as a global public good and focal points of critical 
discussions in transnational public spheres (Calhoun, 2006; Marginson, 2016). Against this growing literature, Riyad Shahjahan offers a thoughtful reflection: higher education researchers and practitioners should look into themselves before they make any attempt to transform their institutions.

This insistence on reflexivity derives from the teachings on mindfulness that frame Shahjahan's paper: you must take care of yourself before helping others; otherwise, you will simply enact your unwholesome mental habits instead of constructively responding to the present situation (Kabat-Zinn, 2013). Shahjahan thus invites researchers and practitioners to stop to examine their ontological and epistemological assumptions that have structured their views of higher education in a globalizing world. Specifically, he illuminates how the debate on the globalization of higher education has been dominated by a certain "onto-epistemic grammar" that naturalizes "anthropocentric, rational, secular and socio-materialistic notions" of being and knowing. Becoming aware of these dominant assumptions, he argues, can open up a space for imagining alternative ways of being and knowing — a prerequisite for critically and effectively transforming higher education institutions in the global age.

To this end, Shahjahan suggests that researchers and practitioners should first generate a "more pluralistic and 'messy' description of globalization of HE" as the basis of their collective deliberation. In a way, he advocates a "cosmopolitical" or "pluriversal" approach to the globalization of higher education (Latour, 2004), which demands collecting "non-modern" and "non-Western" ways of being and knowing, such as interbeing, nonlinear temporality, and spiritual knowledge, that have been rendered invisible by the dominant ontoepistemic grammar of the "modern West." Only when researchers and practitioners embrace such a cosmopolitical project, they can begin a truly global conversation on how to transform higher education, inclusive of diverse ontologies and epistemologies.

In addition to foregrounding the cosmopolitics of higher education, Shahjahan's insistence on reflexivity helps education researchers grapple with their "performative" role in the education system (Callon, 2007). Education researchers may think that they simply describe and explain what is happening to the field of higher education, but they are in fact shaping the field by providing policymakers, university leaders, and other stakeholders with conceptual models and empirical findings as rationales for justifying their decisions (Saito, 2015). Once education researchers fully recognize their performative involvement in the field of higher education, they can begin to rethink and transform their own practices of research, teaching, and consultancy to intervene in the reality of today's higher education. In short, given the feedback loop between theory and practice, education researchers, collectively promoting critical 
reflexivity, have a chance to reorient the trajectory of higher education in a globalizing world.

But exactly how should higher education be reoriented? Or to put it more generally in the overall frame of this special issue, how should educational institutions and practices be re-envisioned in response to the challenges of globalization? Obviously, an answer to this question will likely vary across different economic, social, cultural, and political groups, e.g. class, gender, race, ethnicity, religion, and nationality, as evidenced by a large number of studies of multicultural education (e.g. Banks, 2014; May, 2012). Keeping in mind the fundamentally pluriversal nature of this question, I nonetheless would like to propose two guiding principles with the help of insights on technology (Darvin), mindfulness (Mahalingam), activism (Kennedy and Tadesse), and reflexivity (Shahjahan). In so doing, I draw on Nel Noddings's philosophy of education that emphasizes "one aim of education (and of life itself) is happiness" (2003: 261).

Indeed, the ongoing conversation on how to re-envision education in a globalizing world should not lose sight of the aim of this re-envisioning. Do we, education researchers and practitioners, want to re-envision our institutions and practices because we want young people to better contribute to the global economy, the governance of various global issues, or something else? Here, I believe that learning to live a happy life is one of the most meaningful and important aims of education itself, as Noddings (2003: 261) observed "[h]appy children, growing in their understanding of what happiness is, will seize their educational opportunities with delight, and they will contribute to the happiness of others." I therefore propose to anchor the aim of re-envisioning in happiness.

Central to my proposal is the emphasis on the praxis aspect of happiness against the backdrop of the increasingly popular discourse of happiness. Today, this discourse helps, on the one hand, promote yoga, meditation, and other wellness practices at the individual level and, on the other hand, institutionalize the criteria of well-being at the global level through the United Nations World Happiness Report and other cross-national projects. In so doing, the discourse of happiness often displaces the causes of unhappiness from capitalism, neoliberalism, and other macro systems onto the individual, while imposing the "modern Western" criteria of happiness on the rest of the world à la imperialism (Cabanas and Illouz, 2019; Purser, 2019). Here, it goes without saying that any educational emphasis on happiness as praxis should be undergirded by a 
critical awareness of the world's problems, including socioeconomic inequalities and power asymmetries that the discourse of happiness tends to disguise, and a commitment to alleviating the problems through action.

In light of this praxis-oriented philosophy of education, the first guiding principle is to reconstruct educational institutions and practices around the aim of learning what happiness is and how to attain it at both individual and collective levels. Here, it is crucial to recognize that one's happiness depends on another's, as Noddings (2003: 242) insisted "[o]ur happiness should be threatened by the misery of others." This collective sense of happiness can be fostered through the infusion of technology with mindfulness in educational institutions and practices, which will take seriously the ICT-enabled interconnectedness to encourage collaborations across economic, social, cultural, and political boundaries rather than reinforcing competitions that highlight individual accomplishments. Simply put, the first guiding principle is to help young people learn how to live a happy life together with many different people around the world to whom they are interconnected despite their ontological and epistemological disagreements (Latour, 2005).

The second guiding principle is, "given [t] he satisfaction of needs is a major factor in happiness," to be very careful "in identifying and pursuing inferred needs, and... listen respectfully to what children offer as expressed needs" (Noddings, 2003: 240, 242). For example, when we pursue knowledge activism to transform universities and other educational institutions, we should consult and act with students, perhaps the most immediate and important stakeholders of education. As parents, teachers, administrators, or policymakers, we may well infer some educational needs for young people, given our presumably broader and deeper perspectives by virtue of having lived longer; however, we should also actively listen to educational needs expressed by young people themselves. Equally important, this process of active listening should entail reflexivity in identifying our own needs along with young people's because "happy teachers are more likely to produce happy children" (Noddings, 2003: 252 ). Thus, the very process of reconstructing our educational institutions and practices should bring happiness to ourselves, even though it will no doubt entail many setbacks and disappointments.

In sum, I suggest that happiness be an end and a means of re-envisioning education in a globalizing world: if we, education researchers and practitioners, aim to help young people learn to live a happy life together, we should be happy with our own pluriversal coexistence while negotiating disagreements over how to reconstruct our institutions and practices. I hereby hope that the special issue will help readers in some way to imagine possible and alternative futures for education by taking a fresh look at globalization from the vantage point of technology, mindfulness, activism, reflexivity—and happiness. 


\section{References}

Alvares, C. and Faruqi, S. S, eds. (2014). Decolonising the University: The Emerging Quest for Non-Eurocentric Paradigms. Pulau Pinang: Universiti Sains Malaysia Press.

Banks, J.A., (2014). Diversity, Group Identity, and Citizenship Education in a Global Age. Journal of Education 194(3): 1-12.

Bhambra, G. K., K. Nisancioglu, and Gebrial Dalia, D., eds, (2018). Decolonizing the University. London: Pluto Press.

Bourdieu, P. (1983). The Forms of Capital. In: J. G. Richardson, ed, Handbook of Theory and Research for the Sociology of Education, New York: Greenwood, pp. 241-258.

Bragg, E.A. (1996). Towards Ecological Self: Deep Ecology Meets Constructionist SelfTheory. Journal of Environmental Psychology 16(2): 93-108.

Brooks, R. and Waters, J. (2011). Student Mobilities, Migration and the Internationalization of Higher Education. New York: Palgrave Macmillan.

Brown, P. and Tannock, S. (2009). Education, Meritocracy and the Global War for Talent. Journal of Education Policy 24(4): 377-392.

Burbules, N. C. and Torres, C.A., eds, (2000). Globalization and Education: Critical Perspectives. New York: Routledge.

Cabanas, E. and Ilouz, E. (2019). Manufacturing Happy Citizens: How the Science and Industry of Happiness Control Our Lives. Cambridge: Polity.

Callon, M. (1984). Some Elements of a Sociology of Translation: Domestication of the Scallops and the Fishermen of St Brieuc Bay. The Sociological Review 32: 196-233.

Callon, M. (2007). What Does It Mean to Say That Economics is Performative? In: D. MacKenzie, F. Muniesa, and L. Siu, eds, How Economists Make Markets. The Performativity of Economics, Princeton: Princeton University Press, pp. 311-357.

Castells, M. (2010). The Rise of the Network Society. Malden, MA: John Wiley \& Sons.

Cicchelli, V. and Octobre, S. (2019). Introducing Youth and Globalization and the Special Issue: The Rise and Fall of Cosmopolitanism. Youth and Globalization 1(1): $1-18$.

Corsaro, W. (2018). The Sociology of Childhood Fifth Edition. London: SAGE.

Deardorff, D. K., H. de Wit, J. D. Heyl, and T. Adams (Eds.). 2012. The SAGE Handbook of International Higher Education. London: SAGE.

de Oliveira Andreotti, V. and de Souza, L. M. T., eds. (2012). Postcolonial Perspectives on Global Citizenship Education. New York: Routledge.

Dobson, A. (2003). Citizenship and the Environment. Oxford: Oxford University Press.

Etzkowitz, H. and Leydesdorff, L. (2000). The Dynamics of Innovation: From National Systems and 'Mode 2' to a Triple Helix of University-Industry-Government Relations. Research Policy 29(2): 109-123.

Goren, H. and Yemini, M. (2017). Global Citizenship Education Redefined-A Systematic Review of Empirical Studies on Global Citizenship Education. International Journal of Educational Research 82: 170-183. 
Grossman, P., L. Niemann, S. Schmidt, and Walach, H. (2004). Mindfulness-Based Stress Reduction and Health Benefits: A Meta-Analysis. Journal of Psychosomatic Research 57(1): 35-43.

Hanh, T. N. 1993. Love in Action: Writings on Nonviolent Social Change. Berkeley, CA: Parallax Press.

Hazelkorn, E. (2015). Rankings and the Reshaping of Higher Education: The Battle for World-Class Excellence. New York: Palgrave Macmillan.

Illich, I. 1971. Deschooling Society. New York: Harper \& Row.

Kabat-Zinn, J. 2003. Mindfulness-Based Interventions in Context: Past, Present, and Future. Clinical Psychology: Science and Practice 10(2): 144-156.

Kabat-Zinn, J. 2013. Full Catastrophe Living Revised and Updated Edition: How to Cope with Stress, Pain and Illness Using Mindfulness Meditation. New York: Bantam Books Trade Paperbacks.

Kotler, A. ed. (1999). Engaged Buddhist Reader: Ten Years of Engaged Buddhist Publishing. Berkeley, CA: Parallax Press.

Latham, R. and Sassen, S. eds. (2009). Digital Formations: IT and New Architectures in the Global Realm. Princeton: Princeton University Press.

Latour, B. (2004). Whose Cosmos, Which Cosmopolitics? Comments on the Peace Terms of Ulrich Beck. Common Knowledge 10(3): 450-462.

Latour, B. (2005). From Realpolitik to Dingpolitik or How to Make Things Public In: B. Latour and P. Weibel, eds, Making Things Public: Atmospheres of Democracy, Cambridge, MA: MIT Press, pp. 4-31.

Marginson, S. (2016). Higher Education and the Common Good. Melbourne: Melbourne University Publishing.

May, S. (2012). Language and Minority Rights: Ethnicity, Nationalism and the Politics of Language. New York: Routledge.

Meiklejohn, J., C. Phillips, M. L. Freedman, M. L. Griffin, G. Biegel, A. Roach, J. Frank, C. Burke, L. Pinger, G. Soloway, and Isberg, R. (2012). "Integrating Mindfulness Training into K-12 Education: Fostering the Resilience of Teachers and Students." Mindfulness 3(4): 291-307.

Meyer, J. W. (2000a). Reflections on Education as Transcendence. In: L. Cuban and D. Shipps, eds, Reconstructing the Common Good in Education: Coping with Intractable American Dilemmas, Stanford: Stanford University Press, pp. 206-222.

Meyer, J. W. 20oob. Globalization: Sources and Effects on National States and Societies. International Sociology 15(2): 233-248.

Mitchell, K. 2003. Educating the National Citizen in Neoliberal Times: From the Multicultural Self to the Strategic Cosmopolitan. Transactions of the Institute of British Geographers 28(4): 387-403.

Nilan, P. and Feixa, C., eds. (2006). Global Youth?: Hybrid Identities, Plural Worlds. London: Routledge. 
Noddings, N. (2003). Happiness and Education. New York: Cambridge University Press.

Noddings, N., ed. (2005). Educating Citizens for Global Awareness. New York: Teachers College Press.

Osler, A. and H. Starkey. (2003). Learning for Cosmopolitan Citizenship: Theoretical Debates and Young People's Experiences. Educational Review 55(3): 243-254.

Purser, R. E. (2019). McMindfulness: How Mindfulness Became the New Capitalist Spirituality. London: Repeater Books.

Purser, R. E., D. Forbes, D., and Burke, A., eds. (2016). Handbook of Mindfulness. New York: Springer.

Pusser, B. and S. Marginson. (2013). University Rankings in Critical Perspective. The Journal of Higher Education 84(4): 544-568.

Saito, H. (2010). Actor-Network Theory of Cosmopolitan Education. Journal of Curriculum Studies 42(3): 333-351.

Saito, H. (2011). Cosmopolitan Nation-Building: The Institutional Contradiction and Politics of Postwar Japanese Education. Social Science Japan Journal 14(2): 125-144.

Saito, H. (2015). Cosmopolitics: Towards a New Articulation of Politics, Science and Critique. The British Journal of Sociology 66(3): 441-459.

Saito, H. (2018). Rearticulating the Publicness of Higher Education in a Global World. In: D. Proctor and L. Rumbley, eds, The Future Agenda for Internationalization in Higher Education: Next Generation Insights into Research, Policy, and Practice, New York: Routledge, pp. 168-176.

Schonert-Reichl, K. A. and Roeser, R. W. eds, (2016). Handbook of Mindfulness in Education: Integrating Theory and Research into Practice. New York: Springer.

Spring, J. (2014). Globalization of Education: An Introduction. New York: Routledge.

Stevens, M. L., E. A. Armstrong, and Arum, R. (2008). Sieve, Incubator, Temple, Hub: Empirical and Theoretical Advances in the Sociology of Higher Education. Annual Review of Sociology 34: 127-151.

Stromquist, N. P. and Monkman, K., eds. (2014). Globalization and Education: Integration and Contestation across Cultures. Lanham: Rowman \& Littlefield Education.

Suárez-Orozco, M. M. and Qin-Hilliard, D., eds. (2004). Globalization: Culture and Education in the New Millennium. Berkeley: University of California Press. 